\title{
Exploration and Practice on school-enterprise cooperation personnel training mode of Mechanical Engineering “Excellence Engineer Training Plan” Based on CDIO model
}

\author{
Shao Junpeng ${ }^{1}$ \\ College of Mechanical and Power Engineering \\ Harbin University of Science and Technology \\ Harbin, China \\ sjp566@sina.com
}

\author{
Sui Xiulin ${ }^{2}$, Chen $\mathrm{Si}^{3}$ \\ College of Mechanical and Power Engineering \\ Harbin University of Science and Technology \\ Harbin, China \\ suixiulin@sina.com
}

\begin{abstract}
This paper mainly study the status, existing problem and developing direction of domestic and overseas high engineering education, and discuss the origin, establishing and future development trend of high engineering education under the mode of CDIO engineering education. It also combines with the current situation of Chinese high engineering education, analyzes the feasibility, status quo and implementation effect of personnel training modes under the circumstances of launching "Excellent Engineer Training Plan" in campaigns of Chinese high engineering education. In addition, it describes the implementation process and results of "Excellence Plan" focusing on specialty of mechanical design \& manufacture in Harbin University of Science and Technology.
\end{abstract}

Key words: training mode of excellent engineer; mechanical engineering; CDIO mode, high engineering education

With the advent of the 21st Century and encouraging the development of Chinese high education, education running mode has completed the transition from " elite education to mass education ", as well as converting from the "planned economy " of the ministries and national unity distribution patterns of employment, to cultivate enterprise and university person " two-way selection, multiple selection " direction of development. However, the current transition period has not yet ended, still with impression of elite education mode. At the same time, the university graduates employment still can not shake off to "personal family relationship and the polytropic contact" mode while the proportion for the student directly facing the employment proportion is still very low[1]. High engineering education mode is facing great challenge: how to resolve the contradiction between knowledge transfer and ability training? How to solve the contradiction between ability training and employment satisfying? In order to solve these contradictions, in October of Year 2006, the National Ministry of Education launched the pilot work of education reform in high education, "Excellent Engineer education plan" in the pilot universities like a raging fire spreading to universities across the country. Exploration of high engineering education training mode reform has become a major long-term reform measures in the educational field of China. Ministry of education plans to spend 10 years for 1 million engineers training with high quality range from all fields to achieve the goal of innovated national construction, reserve of talents to achieve modernization and industrialization in addition to dominant in competition of global science and technology[2]. Harbin University of Science and Technology responds with mechanical power engineering college of mechanical engineering and automation specialty to national needs, and long-term educational reform and development. At the same time, combined with the demand for machinery of professional and technical personnel of the society from all walks of life, in 2011 March launched the Harbin University of Science and Technology mechanical professional "excellent engineers plan" and declared a national "Excellence Engineer Training Plan" project as well as the national characteristic specialty related.

\section{DEVELOPMENT OF HIGH ENGINEERING EDUCATION} OVERSEAS AND CDIO ENGINEERING EDUCATION MODE

Improving students' abilities in practice, and enabling students to master professional knowledge and ability for solving practical engineering problems used to be the main purpose of High Engineering Education in twentieth Century. However, with the globalization of the world economy and the development of scientific knowledge, the engineering education vane to the "thick foundation, wide professional" and scientific training mode, that weakens the ability of students to solve practical engineering problems[3]. This development led to the students lack the indispensable awareness of the real engineering situation. I.e. the American Engineering Education firstly transplanted European Engineering Education. There's no systematic theoretical course in this mode, and tutors were mainly firstline engineers, who paid close attention to production practice so to improve problem solving capabilities with regard to education target [4]. After the second half of the20th Century, science and technology were more and more combined with the production along with coming of the 2nd and the 3rd industrial revolution. Thus the modern engineering theory system gradually formed. Engineering education gradually shift to engineering science teaching at places moving from workshop to classroom. Tutors group moved to engineering theory researcher from engineers. However, in recent years, the industrial circles gradually realized serious divorced from reality of the graduates, who failed to meet the real needs of industrial production after training of university engineering. Therefore, many large industrial companies (such as Boeing) had to offer the list 
they needed. In order to settle the contradiction between high education and industrial demand, and adjust the personnel training mode, the United States of America Engineering Accreditation Commission made the largescale adjustment of engineering graduates training target based on the sufficient research. University engineering education should be motive for adjusting personnel training mode, to fulfill the satisfactory of industrial production field. CDIO engineering education model emerged at the times require in this situation, ensuring the high education closely connected with engineering practice.

In year 2000, the Massachusetts Institute of Technology, Chalmer Swedish Institute of Technology, Lin Keping University and Sweden Royal Institute of technology formed a transnational team by Crawley etc. founded the CDIO engineering education model and platform engineering education theory and practice system, and established the international cooperation organization named with CDIO which lasted 4 year with twenty million dollars funding from the Knut and Alice Wallenberg fund, in addition to support from multinational engineering education elite[5]. It was the latest achievement of international engineering education reform in recent years. By year 2010, over 30 of the world famous universities were implementing the CDIO education reform.

CDIO, as a new engineering education idea, advocates whole process of product developing research of CDIO, i.e. Conceive, Design, Implement and Operate, so to cultivate students' capabilities with the process of engineering project life cycle as the carrier, occupation moral, academic knowledge, actual problem solving ability, lifelong learning and team cooperation leadership ability. CDIO engineering education mode, merges training objectives into the whole course system, specifies to the implementation of curriculum and extracurricular practice link, cultivates practical ability under practical teaching, advocates course experiment teaching from practice and creates products for the ultimate goal of teaching after and then return to the actual operation before rise to theory. CDIO connects whole course with the practice, the students' initiative, the way to participate together via project design. CDIO advocates "learning by doing" and "education and learning based on scientific research or engineering project "[6]. CDIO engineering education mode focuses on cultivating the ability to master the basic engineering theory and solid professional knowledge of students. Based on it, it runs through the whole process of training talents team design and innovation in the practice of training, training both excellent professional skills in addition to good occupation morals for internationalization engineers, which is also based on the "trouble system" of education process a model of High Education.

\section{CURRENT STATUS AND DEVELOPMENT OF CDIO EDUCATION MODE FOR CHINESE UNIVERSITY}

In recent 10 years, China pays close attention on research and practice of CDIO engineering education mode, which is an accepted by Ministry of Education, and hopefully to be more attempted by domestic universities.
Absolutely, CDIO, as a new mode from foreign engineering education, maybe adjusted to conform to social characters. Due to the fact of environment and system in China are different from overseas, localization, or similar theory and practice of engineering education may exist with different description or operation would be important.

Based on the CDIO model, combined with the practice of our country, Shantou University introduced, implemented and reformed CDIO engineering education model in year 2005, who has obtained obvious effect. CDIO engineering education reform committee established by Polytechnic Institute of Shantou University, who organized all teaching staff of repeatedly group learning and discussing training program of the standard of CDIO. The contrast program, gaps identifying, practice focusing, objectives. In year 2006, Technology Institute of Shantou University took the lead in the engineering education reform, and the mode based on morality and integrity, targeted on four capabilities as main training objective. The mode requires that each professional ability syllabus as the basic, with 4 to 6 practical and exploratory team design projects as the main carrier. It promotes students' ability by measurement of integrating and systematic concept. Part of the valuable reform experience and the fruitful results of Technology Institute of Shantou University, has been collected and published with several papers in " World Transaction on Engineering and Technology Education" sponsored by UNESCO. In $2^{\text {nd }}$ half January of year 2006, the International Committee of CDIO, agreed to accept Chinese College of Shantou University to become the first member of CDIO after strict examination. In June of year 2006, Shantou University introduced their reform experience of CDIO by the participation of $2^{\text {nd }}$ of the CDIO conference by Linkoping University in Sweden. In November of year 2007, Shantou University organized the "2007 China's High Engineering Education Reform Forum" and "CDIO international cooperation conference". Experts and scholars from domestic and foreign universities and industry more than 40 units gave recognition when participating in the meeting and the effects of CDIO engineering education reform in Shantou University [7].

In December of year 2008, "2008 China CDIO engineering education seminars and pilot job conference" held at the Shantou University, sponsored by the Department of high education science and Technology Department. At the same time, "1st session of China CDIO engineering education research and practice" launched with the high education department, where discussed the issues on how to set up the first batch of pilot innovative CDIO model, and determined the first batch of pilot units, the pilot work of the working group list for group work plan and operation management mechanism. In addition, mechanical, electrical, chemical, civil engineering and light industry five major categories as options were preliminary recommended, followed by discussion of the professional working group of the scope of work, cooperation and work plan. After discussion, 1st batch of CDIO pilot colleges and universities list of total 18 ones announced, and the meeting decided to establish CDIO model innovation pilot working group composed of Shantou University, as leader working group 
and the Secretariat permanent location, with deputy head as Chengdu University of Information Technology. Yanshan University, Chengdu University of Information Technology, Guangzhou University and HeFei University of Technology, acted as the mechanical, electrical, chemical and civil engineering professional group convener [8].

Dr. Gu Xueyong, as professor of industrial engineering Dept. in Tsinghua University, who served as a software engineer in MIT of United States tutored by Ed. Crawley professor over decades in rich experience of the theory and engineering practice, has made outstanding achievements in courses of "data structure" and "database technology" with CDIO creative method of teaching. Under the guidance of Dr. Gu, students made a historical learning result through the project learning, based on active learning, active practice, and they generally believed it as a perfect learning which greatly enhanced the ability of self-study, R\&D, solving problems, team work and interpersonal communication.

Electrical engineering and its automation institute of Fujian University of Technology, become one of the CDIO engineering education reform pilot universities of Ministry of Education in 2008. They introduced CDIO mode of engineering training into Electrical engineering education, with combination of present condition of University focusing on Haixi economic construction and talent demand, and link organically between school and enterprise via CDIO while study and work out the CDIO professional teaching program so to complete UEC-CDIO reform project. It highlights the characters of talents ability structure, strengthens reform on teaching methods and measures and cultivates advanced engineering and technical applied talents who would meet the demand of production, construction, management and service for electrical engineering and automation fields.

Mechanical and electronic engineering of Beijing Institute of Petrochemical Technology, was evaluated as characteristic specialty for special CDIO mode talent training by the Ministry of Education, who applied CDIO engineering education mode into practice of teaching for students of mechanical electronic engineering specialized 07 grade that revealed the learning in doing. Abilities of selflearning, problem solving, team work and co-ordination were greatly enhanced for learners due to project-based concept for educating and learning.

The Guangzhou University, as one of the1st batch of pilot universities for CDIO, made some achievements during exploring advantages for the local pilot combining with the traditional mode of education. The teachers from mechanical engineering and automation specialty, started CDIO learning from the second half of 2008, who combined local characteristics, traditional mode of education with CDIO learning to form their own characteristics. They mainly did research on merging traditional engineering education with CDIO education mode considering characteristics of local universities, and deeply explored the relationship and how to link between two teaching modes, in addition to education program and working rules under innovation mode of CDIO in the condition of merging. Research on both CDIO education influences on local university conditions and CDIO education model adaptability have been done deeply at the same time.

\section{OPERATION AND STATUS OF "EXCELLENT ENGINEER EDUCATION AND TRAINING PROGRAM" IN CHINA}

"Scientists have known the world, engineers to create the future of the world". How to cultivate engineering and technical personnel with social needs, and how to develop a truly outstanding engineer, is the focused issue for domestic and overseas education fields, and it is also the task for all world. The US comes up with the plan "Engineer Education Program in 2020", Germany, and France and other industrialized countries also own a complete engineer education system, which has just started in our country. As the proceed of industrialization and urbanization, China will continue to maintain significant engineering construction scale, therefore the tracking and lead of many key projects depend on the engineering and technical personnel who will make them come true in the future for a long period. In recent years, the demand for Excellence Engineer's voice is high in industry fields. Those who will achieve safe production, improve the products quality, promote energysaving emission reduction, and enhance the core competitiveness of enterprises, are to be cultivated as national excellent engineering in sufficient quantity facing the production line. To reach this goal, the Ministry of Education implemented "Excellence Engineer Education Program" in October of 2006, focusing on "cultivating a large number of technical personnel and high quality engineers with innovative ability to meet the demand for economic and social development". "Excellence Engineer Education Program" requires its implementation layer composing with bachelor, master and doctor into site engineer, design engineer and research engineer for backup. This plan is characterized as three notable features: one is the industry and enterprise participating for at lease one year in factory guaranteed during 4 years learning; second is training plan with general standards and industry standards, third is to strengthen the engineering and innovation ability for students encouraging students with engineering consciousness and practice to form a solid foundation in the future when engaged in technical work. After 5 years of operation with fruitful result for "excellence program", and below examples show.

The Institute of energy and environmental engineering from Shanghai University of Electric Power, proposed training program of professional excellence Engineer Thermal Energy and power engineering according to their own specialty features. They chose two modes: "order from factory" and "industry built", one is organized by high-grade students, the other is planned directly in the enrollment. The first training program called "enterprise order" which is to say admittance. Students sign up against specified requests of enterprises, such as third grade students, good credits, certain English and computer skills or other requirements of the joining enterprise. Second program called "industry built" which means to establish a number of engineers or number of classed to be educated, included in the enrollment plan, such as defining as thermal energy and 
Power Engineering Excellence Engineer class according to the status of enterprises or their alliance in this industry field. The students are to be educated with outstanding engineers program while their records managed with school rules. In the program implementation process, they will be treated as a professional direction, follow the admission rules, respect the candidates will. For example, if enrollment number is insufficient, adjustment would be done from other specialty following the same regulations, also the school uniform management and exit mechanism in the follow-up training. Approved by the Department in charge of education, those who complete the "excellent engineers plan" can get both the diploma of undergraduate and school "Excellence Engineer Plans" certificate, degree shall be awarded in accordance with the "awarded a bachelor's degree work implementation details".

Institute of energy and power engineering from Wuhan University of Technology, regarded the implementation of "Excellence Engineer education program" as an important opportunity to develop and major teaching reform project in High Engineering University with reference to successful experience of advanced countries in the world, and decided to cooperate with enterprises as a platform focusing the curriculum system reform as target actively exploring new mode of talent energy power system and automation professional training on the basis of outstanding engineers, training objectives, outstanding engineers and the professional standards of excellent engineer education to reform the old teaching system three aspects scheme. Training target is to cultivate innovative ability, adaptable to the practical engineering needs of the rapid development of China's society and economic. The cultivation of professional standards are: professional training under national standard, basic requirements from industry standard, combined with the school characteristics, energy and automation school idea and the orientation of talent cultivation, cultivation standard and implementation of matrix formulation of energy power system and automation professional engineer professional excellence which including: knowledge and skills, personal qualities and engineering practice, the three part. Stage training program are composed of: main subject: ship and ocean engineering, power engineering and engineering thermal physics, mechanical engineering; the main course: Mechanical Engineering, mechanical design basis, electrical and electronic technology foundation, engineering thermodynamics, heat transfer, fluid mechanics $B$, the automatic control principle and application $\mathrm{B}$, the energy and power, mechanical testing technology the internal combustion engine, power plant theory and design, power machinery manufacturing and repair, refrigeration compressor, refrigeration principles and equipments etc.. Special courses: combustion engine, power plant theory and designing, power machinery manufacturing and repair. Duration: 4 years, and in the school curriculum to study for 3 years, 1 years of business practice. Degree: Bachelor of engineering and field engineer qualification. Wuhan University of Technology energy power system and automation professional excellence engineer project pilot class every year plans to recruit 35 people. Zero batch separate enrollment would be applied with merit-based selection based on performance. The basic system of field engineer for the undergraduate 4 years, after the completion of their studies awarded bachelor's degree and site engineer qualification. The experimental class students excellent engineer project of $50 \%$ can enter graduate study, into the design development engineer training stage. Graduate school system for 2 years, after the completion of their studies to grant master's degree of Engineering in engineering and Design Engineer qualification.

Institute of communication and information engineering from Xi'an University of Science And Technology, strengthened the practice and innovation ability of college students of engineering culture and accelerate the reform of practice teaching in accordance with national "Excellence Engineer Training Plan" requirement, paying attention to the construction of a multi-level system of practical teaching. Practical teaching system is divided into three levels: basic practice of professional practice of comprehensive professional practice of some engineering foundation education in engineering mathematics. For example, engineering mathematics strengthens the engineering foundation by method of mathematical modeling course research and work practice. Base for practice was established by the power grid safety monitoring systems laboratory data network system laboratory exchange systems laboratory and transmission systems laboratory, mainly carries on the practice of communication system and network technology, according to the professional characteristics, to establish open 12 hours a day practicing professional management model based laboratory base of full-time teachers, responsible for scheduling, students according to their own interest and time independent arrangement of experiments, to improve the students' enthusiasm for experimental procedures, provide the corresponding experiment platform for training the students' ability to innovate. In the school has established more than 4 practice bases, 9 professional practice bases.

\section{THE SPECIALTY "EXCELLENT ENGINEERS PLANS" TRAINING MODE AND PRACTICE EFFECT}

Specialty of mechanical design \& manufacture in Harbin University of Science and Technology became the second batch of "Excellence Engineer education professional pilot program" of the Ministry of education in 2011. Institute of power engineering machinery, cooperated with Zhejiang Xinya group in the "Excellent engineers training plan", has carried on the positive exploration, in-depth cooperation practice base for students' practice and training, and in June 23, 2011 the "Excellent engineers plan" practice base signing ceremony. At the same time, and Qiqihar Heavy CNC equipment Limited by Share Ltd, Dalian Innovation parts manufacturing company, the Fuchun River electrical and Mechanical Co., Ltd., Hafei group, Harbin engineering machinery plant, Jinzhou crane factory more than 10 enterprises have signed the excellent engineers training contract. 
2011 September to 2012 June, mechanical design manufacturing and automation professional 37 students of the first session of "excellence engineers" experimental class, graduation project enterprise stage design teaching of engineering practice was carried out in Wenzhou New Asia Electronics Company. The teacher during the cooperation enterprise technical personnel and school assignment, combined with the enterprise demand for talents, which includes enterprise management, staff quality, 5S management, equipment operation, engineering technology, enterprise training and numerical control technology, computer aided design, technology and English teaching theory and practice of learning (Figure 1) .On this basis, the students in each post company for practice give full play to the theory of solid, strong communication skills and other advantages, to contribute their own strength for the production and technical innovation company was approved by the company, won the praise of employees. The students in the internship enhanced the ability for integration of theory with practice, hard working, and found their employment and development direction.

During the internship, according to the characteristics of their products, combining production research and development needs, graduation design topic of school teachers and enterprise engineering and technical personnel jointly developed the pilot class, all the problems are focused on solving technical problems existing and development of new enterprises and the difficulties encountered in the establishment of. Management to the enterprises in Zhejiang New Asia Electronics Company and the technical staff is to report the results back to school before, enterprises have been recognized and widely acclaimed.

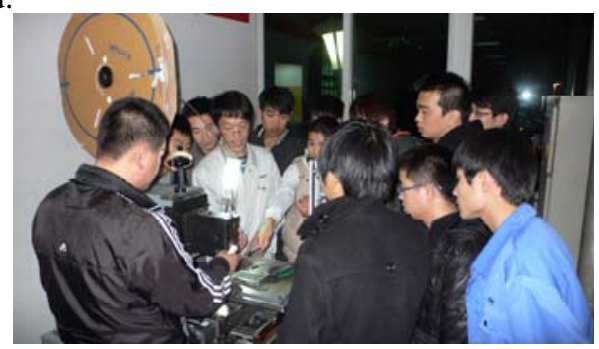

Figure 1. Investigate Enterprise project design conditions

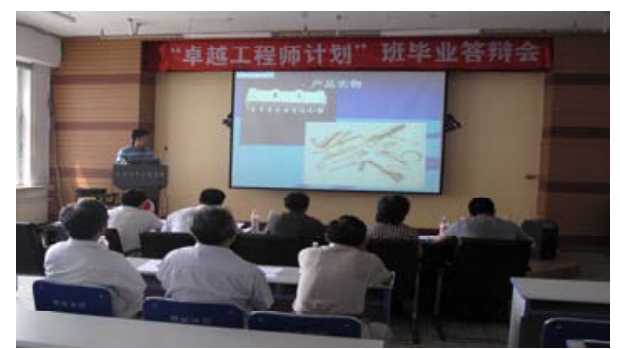

Figure 2. "Excellent engineers " class graduates defense

On June 26, 2012, " excellent engineers plan" class participated in the school-organized of undergraduate graduation debate(Figure 2), the dean of College of power and mechanical engineering, Shao Junpeng was appointed chairman of the defense committee members, including Vice President Sui Xiulin, deputy director of the Department of Jiang Bin, director of manufacturing Wang Yiwen, Zhejiang New Asia Electronics Huang Ren Ji manager and teacher $\mathrm{Wu}$ Xuefeng et al. The students graduate design, enrich the content of the respondent stated clearly, clarity, the Defense Committee and supervision of recognized experts, all students are successfully completed the respondent, including Zheng Wenjuan, 6 students won outstanding.

Experiences accumulated in the first pilot class, School of mechanical engineering, mechanical design manufacturing and automation professional will continue to advance the implementation of the " outstanding engineers plans ", in-depth cooperation with Zhejiang Xinya group enterprises, improve the theory with the practice of the teaching level, and will open up more cooperative enterprises. "Excellent Engineer Plan" will be fully extended. The establishment of University, enterprise personnel training "production, learning and research, " four in one of the innovation education mechanism, give full play to the role in the engineering personnel training, improve students' engineering quality, practical ability of students in engineering, engineering design and engineering innovation ability.

\section{ACKNOWLEDGMENT}

This research was sponsored by Teaching Reform of High Education Pilot Project of Heilongjiang Province (No. JG2201201110).

\section{REFERENCES}

[1] Edward, F.Crawley, Johan Malmqvist, Zha Jianzhong, etc. "Environment of engineering education," vol. 04. High Education of Engineering. 2008, pp.13-21.

[2] ZhaJian Zhong. "strategy of Engineering education reform CDIO University-industry cooperation and international," vol. 05. University Teaching in China. 2008, pp.16-19.

[3] Liurong Pei, Shiqing Nan, Chen Yang Jian, etc. "CDIO engineering education mode,” vol. 05. China Metallurgical Education. 2011, pp.913.

[4] Taoyong Fang, Shangcun Hui. "CDIO Outline revelation of high engineering education innovation,” vol. 11. China's High Education Research. 2006, pp.81-83.

[5] Kangquan Li, Xiaohua Lu, Guangjing Xiong. "CDIO Outline and Personnel training of engineering innovation,” vol. 04. High Education Research.2008, pp.15-18.

[6] Peihua Gu, Minfen Shen, Shengping Li, etc. "From CDIO to EIPCDIO Shantou University engineering education and Exploring talent training model," vol. 01. High Education of Engineering. 2008, pp. 21-28.

[7] Peihua Gu, Sheng-ping Lee, Minfen Shen, etc. "EIP-CDIO designoriented innovative engineering training model," vol. 03. High Education in China. 2009, pp.47-49.

[8] Huan Lei, Weiyi Tang, Edward F, Crawley Edward E. "cultivate engineering technological talents of innovative multi-level specialization," vol. 05. High Engineering Educational Research. 2009, pp.29-35. 